\title{
Effect of Annealing on the Optical Properties of (PVA-CuCl) Composites
}

\author{
Sabah A. Salman, Nabeel A. Bakr, Marwa R. Jwameer \\ Department of Physics, College of Science, University of Diyala, Diyala, Iraq \\ Email: sabah_anwer74@yahoo.com
}

Keywords: Optical Properties, Polyvinyl alcohol (PVA), Copper Chloride, Composites.

\begin{abstract}
Films of polymer (polyvinyl alcohol (PVA)) doped with $\mathrm{CuCl}$ salt at different concentrations (2 and 10) wt\% were prepared using casting technique. The optical properties of the films were studied after annealing. The transmission and absorption spectra have been recorded in the wavelength range of (300-1100) nm. The effect of annealing on the optical properties for (PVA$\mathrm{CuCl}$ ) films with different concentrations (2 and 10) $\mathrm{wt} \%$ of copper chloride salt shows that the transmittance decreased after annealing for all the films. The optical constants (absorption coefficient, refractive index, extinction coefficient, real and imaginary parts of dielectric constant) for all the films are affected by annealing. The energy gap $\left(E_{g}\right)$ of all the films decreased after annealing.
\end{abstract}

\section{1- INTRODUCTION}

Polymers have existed in natural form since life began and those such as DNA, RNA, proteins and polysaccharides play crucial roles in plant and animal life. From the earliest times, man has exploited naturally-occurring polymers as materials for providing clothing, decoration, shelter, tools, weapons, writing materials and other requirements [1].

The properties of polymer-mineral reinforced composites are determined by the component properties (particle shape, surface area, surface chemistry, polymer microstructure) and by the preparation method and processing conditions as well. Among of preparation methods, injection molding has strong influence on the internal microstructure of polymers and in a consequence on mechanical response of the material [2]. Nowadays, thermoplastic polymers are widely used in various aspects of human society. They have several good properties such as good chemical resistance, better mechanical properties, cost effectiveness; that make them the polymers of choice for numerous applications. Due to superior properties of these materials, they have been used mixed with natural fillers and in manufactured composite forms as well. The use of thermoplastic polymer composites reinforced with natural fillers has been rapidly increasing in the automotive industry [3].

Polyvinyl alcohol (PVA) is a water-soluble synthetic polymer. Due to the characteristics of easy preparation, good biodegradability, excellent chemical resistance and good mechanical properties, (PVA) has been used in many biomaterial applications [4]. Doping of polymers attracted the scientific and technological researchers, because of their wide applications. The dopants in polymer can change the molecular structure and hence the microstructure as well as the macroscopic properties of the polymer [5].

\section{2- MATERIALS AND METHODS}

The materials used in this work were as a powder of polymer (polyvinyl alcohol (PVA)) doped by copper chloride $\mathrm{CuCl}$ salt with weight percent $(2$ and 10$) \mathrm{wt} \%$. It was dissolved in (15 ml) of distilled water in glass beaker by using magnetic stirrer for about (45 minute) and placed in Petri dish ( $5 \mathrm{~cm}$ diameter) using casting technique to prepare the films. The thickness of the dried films is $(45 \mu \mathrm{m})$ measured by digital micrometer. The transmission and absorption spectra of (PVA-CuCl) films have been recorded in the wavelength range of (300-1100) $\mathrm{nm}$ using the UV-Visible 1800 double beam spectrophotometer provided by Shimadzu, Japanese company. All the films are annealed at temperature of $\left(80^{\circ} \mathrm{C}\right)$ for $(1 \mathrm{~h})$ using the oven provided by Memmert German Company. 


\section{3- RESULTS AND DISCUSSION}

Figure (1) shows the transmission spectra of (PVA-CuCl) films with 2 and 10 wt\% concentrations of $\mathrm{CuCl}$ salt as a function of the wavelength before and after annealing. The figure shows that the transmittance increases with the increase in wavelength for all the films. It is clear that the transmittance decreased after annealing for all the films and this result is in agreement with previous reports [6-8].

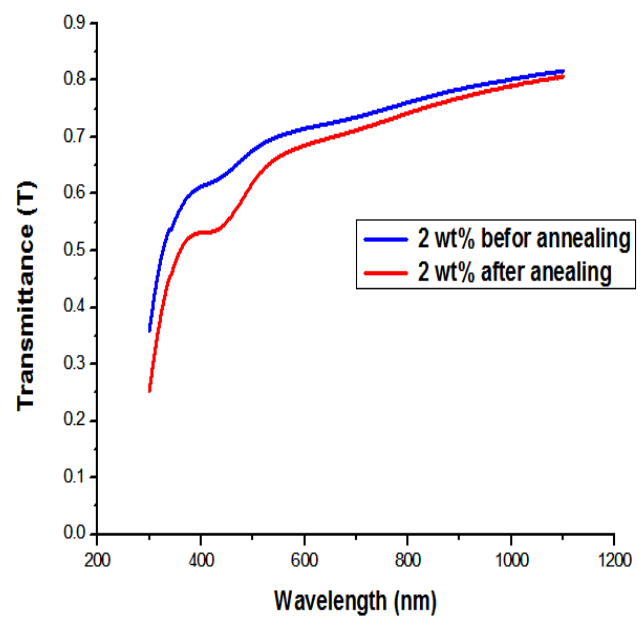

(a)

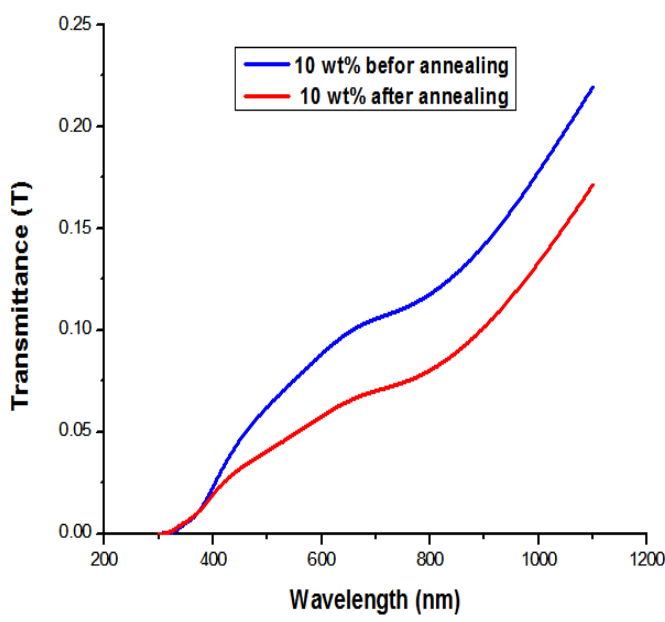

(b)

Figure (1): The transmittance of (PVA-CuCl) films with 2 and $10 \mathrm{wt} \%$ concentrations of $\mathrm{CuCl}$ salt as a function of the wavelength (a) before annealing and (b) after annealing.

Figure (2) shows the absorption spectra of (PVA-CuCl) films with 2 and $10 \mathrm{wt} \%$ concentrations of $\mathrm{CuCl}$ salt as a function of the wavelength before and after annealing. The figure shows that the absorbance decreases with the increase in wavelength for all the films. This behavior can be explained as follows: at high wavelengths the incident photons don't have enough energy to interact with atoms, the photon will transmit. When the wavelength decreases, the interaction between incident photon and material will occur and then the absorbance will increase [9]. Also, from this figure, it is clear that the absorbance increased after annealing for all the films.
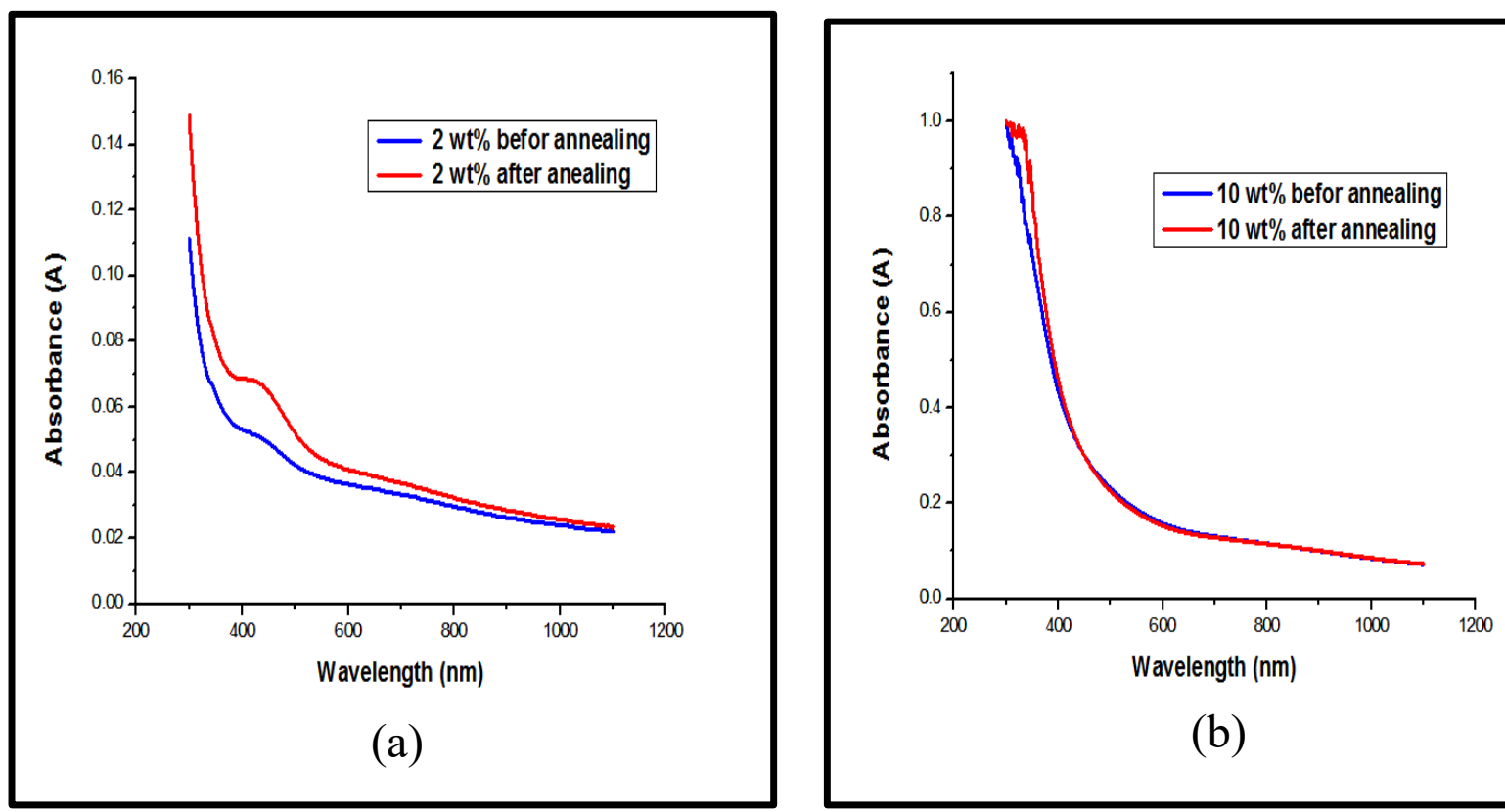

(b)

Figure (2): The absorbance of (PVA-CuCl) films with 2 and $10 \mathrm{wt} \%$ concentrations of $\mathrm{CuCl}$ salt as a function of the wavelength (a) before annealing and (b) after annealing. 
Figure (3) shows the absorption coefficient of (PVA-CuCl) films with 2 and 10 wt\% concentrations of $\mathrm{CuCl}$ salt as a function of the wavelength before and after annealing. The absorption coefficient $\alpha(\mathrm{cm})^{-1}$ is calculated using the following equation [10]:

$$
\alpha=2.303\left(\frac{A}{t}\right)
$$

Where (A) is the absorbance and (t) is the thickness of the film.

It can be observed that in the shorter wavelengths the absorption coefficient exhibits high values which means that there is a large probability of the electron transition [11] and then the absorption coefficient decreases with increasing the wavelength for all the films. It is also found the absorption coefficient for (PVA-CuCl) films is less than $\left(10^{4} \mathrm{~cm}^{-1}\right)$, which explains that the electron transition is indirect. Moreover, it becomes clear that the absorption coefficient increased after annealing for all the films. However the increase in absorption coefficient after annealing is due to its dependence on the absorbance, and due to the decrease in defects as well [12].
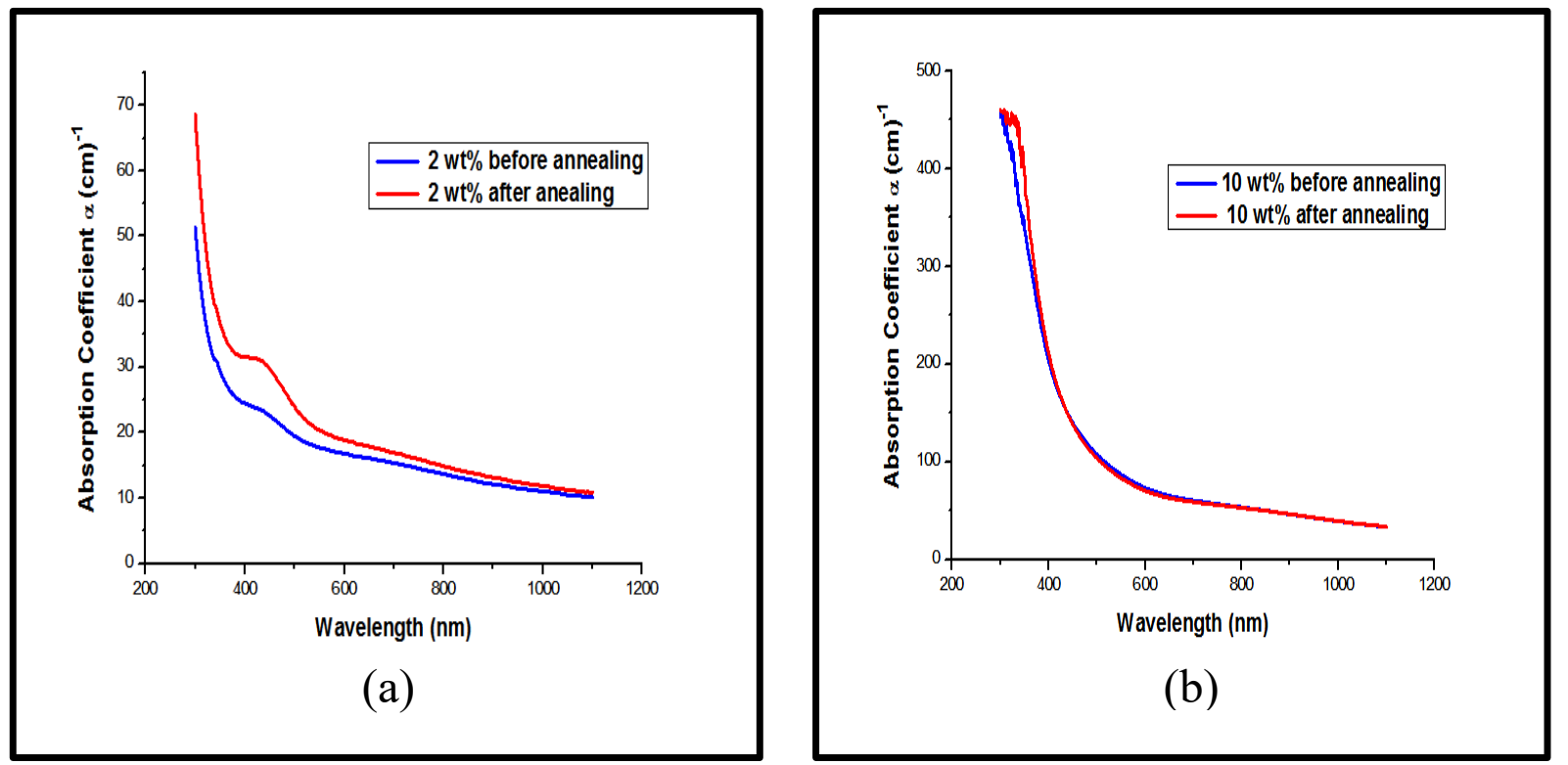

Figure (3): The absorption coefficient of (PVA-CuCl) films with 2 and $10 \mathrm{wt} \%$ concentrations of $\mathrm{CuCl}$ salt as a function of the wavelength (a) before annealing and (b) after annealing.

The energy gap $\left(E_{g}\right)$ for the allowed indirect transition is calculated using the following equation [13]:

$$
\alpha h v=B\left(h v-E_{g}\right)^{2}
$$

Where (B) is constant inversely proportional to amorphousity and (hv) is the photon energy.

Figure (4) shows the relation between $(\alpha \mathrm{h} v)^{\mathbf{1} / 2}$ of $(\mathrm{PVA}-\mathrm{CuCl})$ films with 2 and $10 \mathrm{wt}^{\mathrm{O}} \%$ concentrations of $\mathrm{CuCl}$ salt as a function of the photon energy before and after annealing. On drawing a straight line from the upper linear part of the curve towards the (x-axis) at the value of $(\alpha h v)^{1 / 2}=0$ one gets the energy gap $\left(\mathrm{E}_{\mathrm{g}}\right)$ for the allowed indirect transition. It is observed that the absorption edge shifts to lower energy and the energy gap $\left(\mathrm{E}_{\mathrm{g}}\right)$ of $(\mathrm{PVA}-\mathrm{CuCl})$ films decreases after annealing for all the films comparing to that before annealing. The shift in the absorption edge with the heat treatment is explained by a change in the defect structure of solids. This states in the band structure is responsible for the low values of energy gap $\left(E_{g}\right)$ [14], and also because the reduction of the band gap of these films after thermal treatment and shifting the absorption properties of these organic molecules to lower energy often give rise to stability problems to oxidation [6]. Table (1) 
shows the values of energy gap $\left(\mathrm{E}_{\mathrm{g}}\right)$ for the allowed indirect transition of (PVA-CuCl) films with 2 and $10 \mathrm{wt} \%$ concentrations of $\mathrm{CuCl}$ salt before and after annealing.

Table (1) Values of energy gap $\left(\mathrm{E}_{\mathrm{g}}\right)$ for the allowed indirect transition of (PVA- $\mathrm{CuCl}$ ) films with 2 and $\mathrm{wt} \%$ concentrations of $\mathrm{CuCl}$ salt before and after annealing.

\begin{tabular}{|c|c|c|}
\hline $\begin{array}{c}\text { concentration } \\
(\mathbf{w t} \%)\end{array}$ & $\begin{array}{c}\text { Before annealing } \\
\left(\mathbf{E}_{\mathbf{g}}\right) \mathbf{e V}\end{array}$ & $\begin{array}{c}\text { After annealing } \\
\left(\mathbf{E}_{\mathbf{g}}\right) \mathbf{e V}\end{array}$ \\
\hline $\mathbf{2}$ & 3.457 & 2.977 \\
\hline $\mathbf{1 0}$ & 2.187 & 2.01 \\
\hline
\end{tabular}

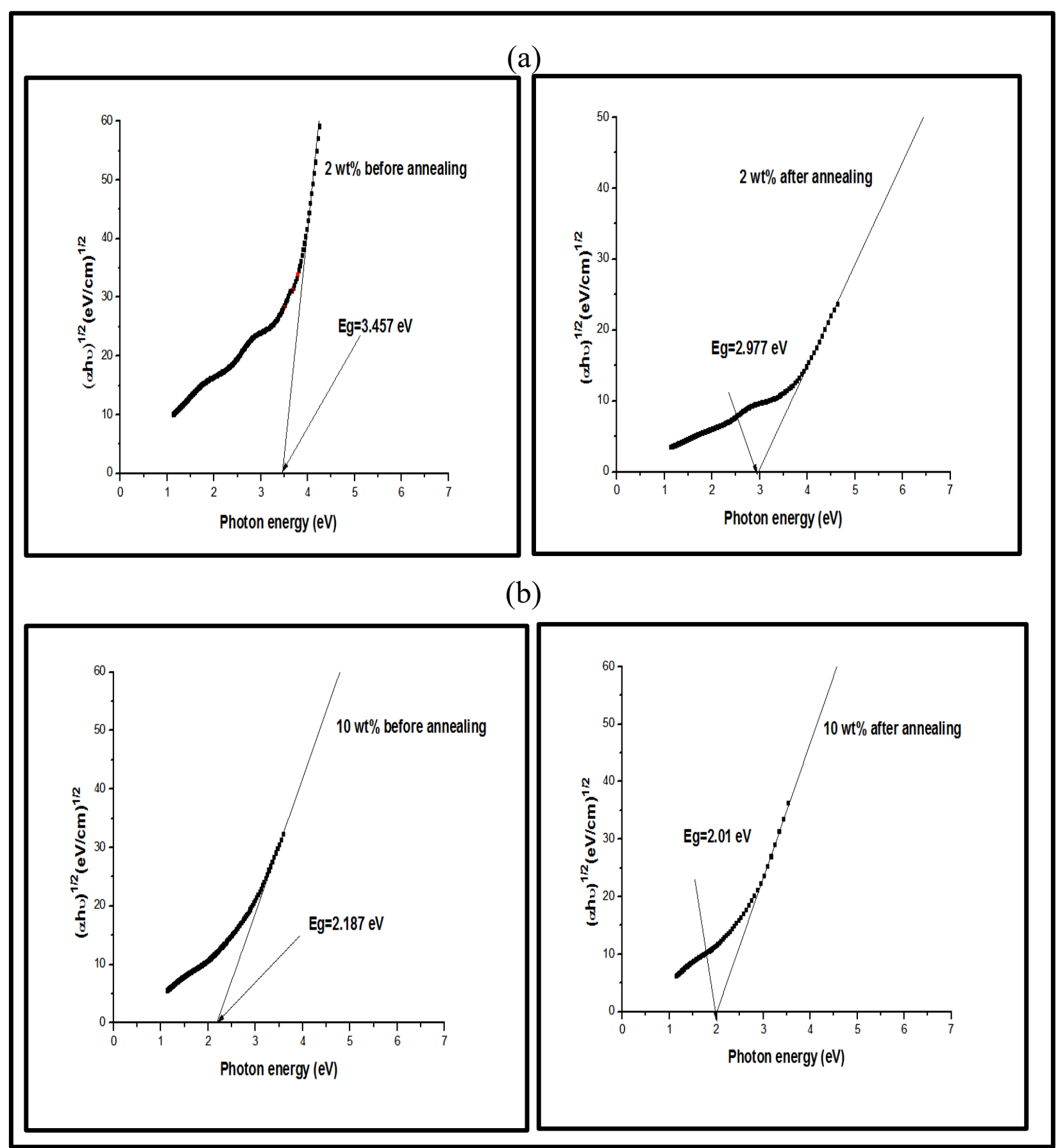

Figure (4): The energy gap $\left(\mathrm{E}_{\mathrm{g}}\right)$ for the allowed indirect transition of (PVA-CuCl) films with 2 and $10 \mathrm{wt} \%$ concentrations of $\mathrm{CuCl}$ salt (a) before annealing and (b) after annealing. 
Figure (5) shows the change of refractive index of (PVA-CuCl) films with 2 and 10 wt\% concentrations of $\mathrm{CuCl}$ salt as a function of the wavelength before and after annealing. The refractive index (n) is calculated from the equation [15]:

$$
\mathrm{n}=\sqrt{\frac{4 \mathrm{R}-\mathrm{k}^{2}}{(\mathrm{R}-1)^{2}}}-\frac{(\mathrm{R}+1)}{(\mathrm{R}-1)}
$$

Where $(\mathrm{R})$ is the reflectance and $(\mathrm{k})$ is the extinction coefficient.

It is observed that the refractive index increased after annealing for all the films.

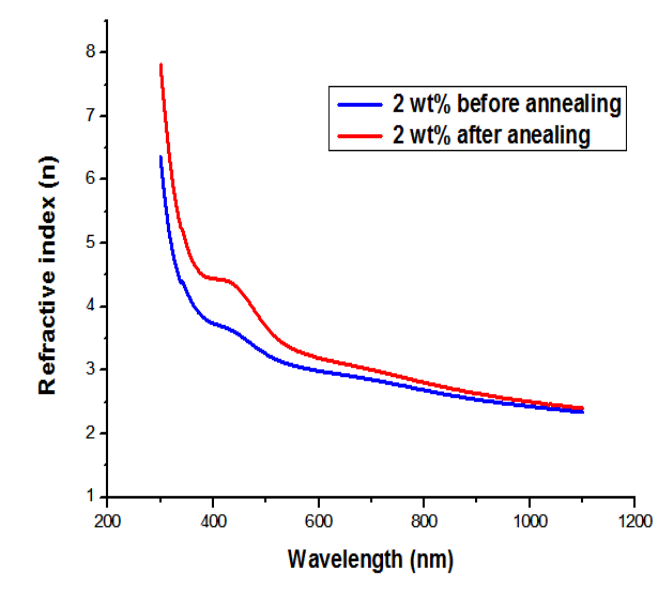

(a)

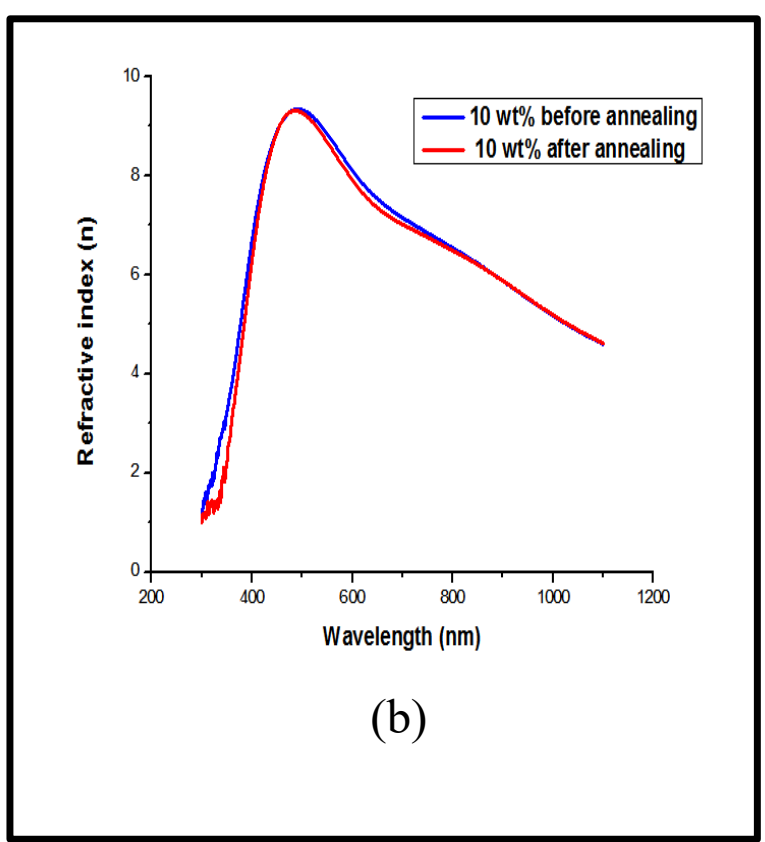

Figure (5): The refractive index of (PVA-CuCl) films with 2 and $10 \mathrm{wt} \%$ concentrations of $\mathrm{CuCl}$ salt as a function of the wavelength (a) before annealing and (b) after annealing.

Figure (6) shows the change in extinction coefficient of (PVA-CuCl) films with 2 and $10 \mathrm{wt} \%$ concentrations of $\mathrm{CuCl}$ salt as a function of the wavelength before and after annealing. The extinction coefficient $(\mathrm{k})$ is calculated from the equation [16]:

$$
k=\frac{\alpha \lambda}{4 \pi}
$$

Where $(\lambda)$ is the wavelength of incident ray.

The figure shows that the extinction coefficient increased after annealing for all the films. This is attributed to high absorption coefficient because the behavior of extinction coefficient is nearly similar to the corresponding absorption coefficient. 


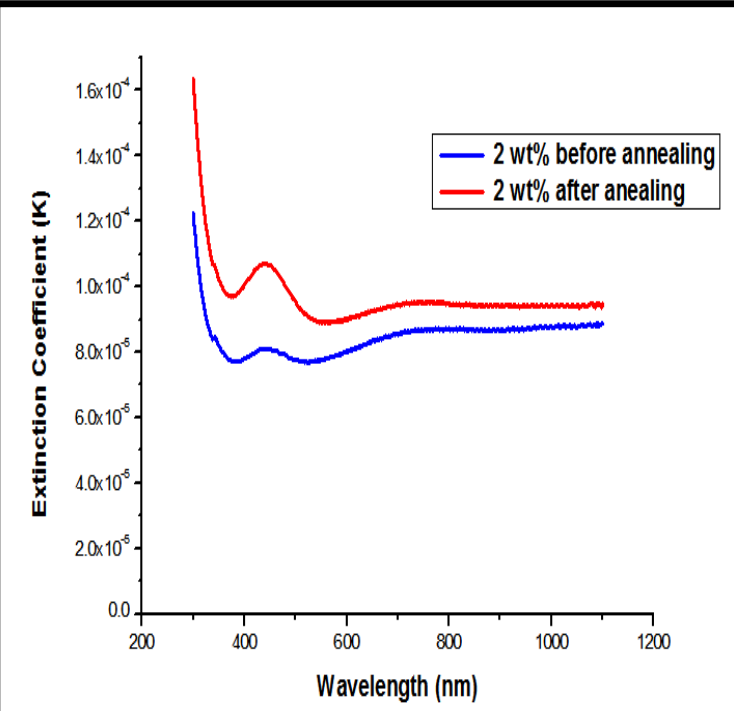

(a)

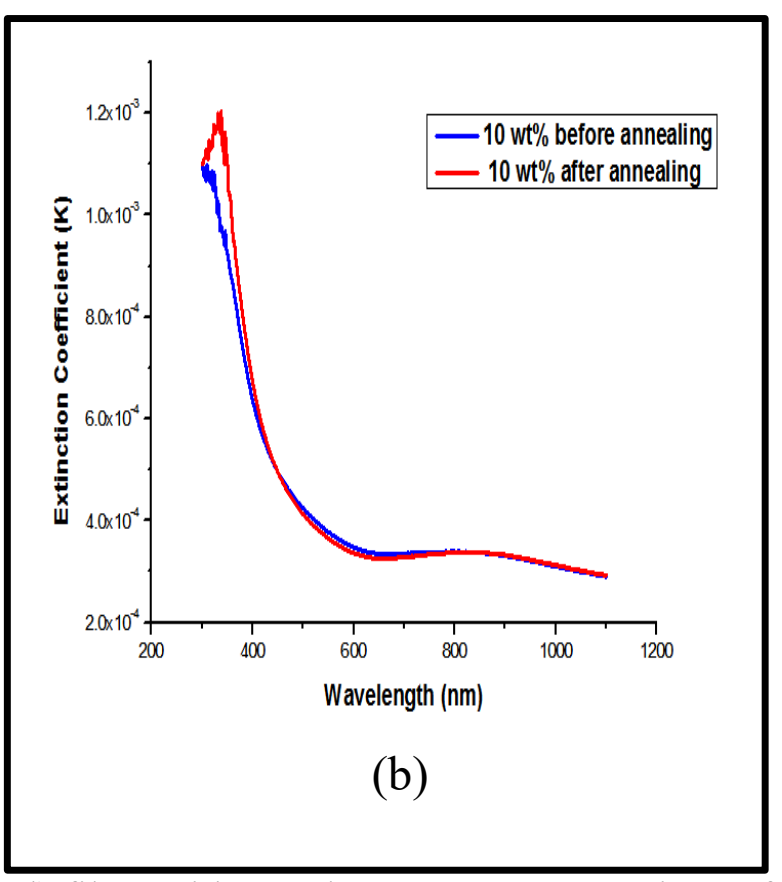

Figure (6): The extinction coefficient of (PVA-CuCl) films with 2 and $10 \mathrm{wt} \%$ concentrations of

$\mathrm{CuCl}$ salt as a function of the wavelength (a) before annealing and (b) after annealing.

Figures (7) and (8) show the change of the real and imaginary parts of dielectric constant of (PVA- CuCl) films with 2 and $10 \mathrm{wt} \%$ concentrations of $\mathrm{CuCl}$ salt as a function of the wavelength before and after annealing. The real $\left(\varepsilon_{1}\right)$ and imaginary $\left(\varepsilon_{2}\right)$ parts of dielectric constant can be expressed by the following equation [17]:

$$
\begin{aligned}
& \varepsilon_{1}=n^{2}-k^{2} \\
& \varepsilon_{2}=2 n k
\end{aligned}
$$

It can be seen that the real and imaginary parts of dielectric constant increased after annealing for all the films. This behavior is similar to $(\mathrm{n})$ and $(\mathrm{k})$ because $\left(\varepsilon_{1}\right)$ depends on $\left(\mathrm{n}^{2}\right)$ due to low value of $\left(\mathrm{k}^{2}\right)$, while $\left(\varepsilon_{2}\right)$ is dependent on $(\mathrm{k})$ value which depends on the $(\alpha)$. The real and imaginary parts of dielectric constant indicate the same pattern and the values of real part are higher than the values of imaginary part $[6,8]$.

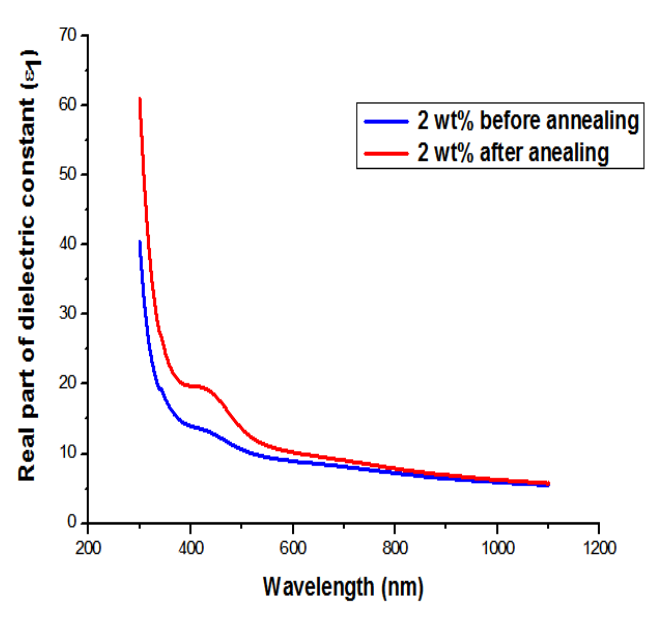

(a)

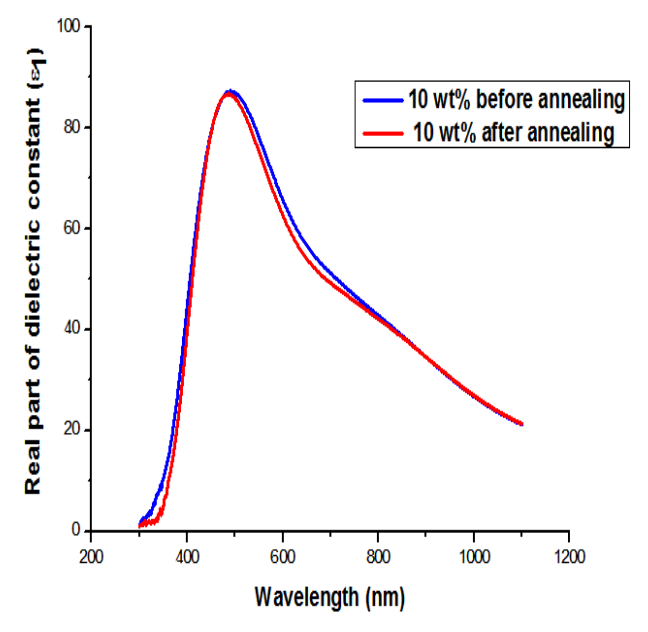

(b)

Figure (7): The real part of dielectric constant of (PVA-CuCl) films with 2 and $10 \mathrm{wt} \%$ concentrations of $\mathrm{CuCl}$ salt as a function of the wavelength (a) before annealing and (b) after annealing. 

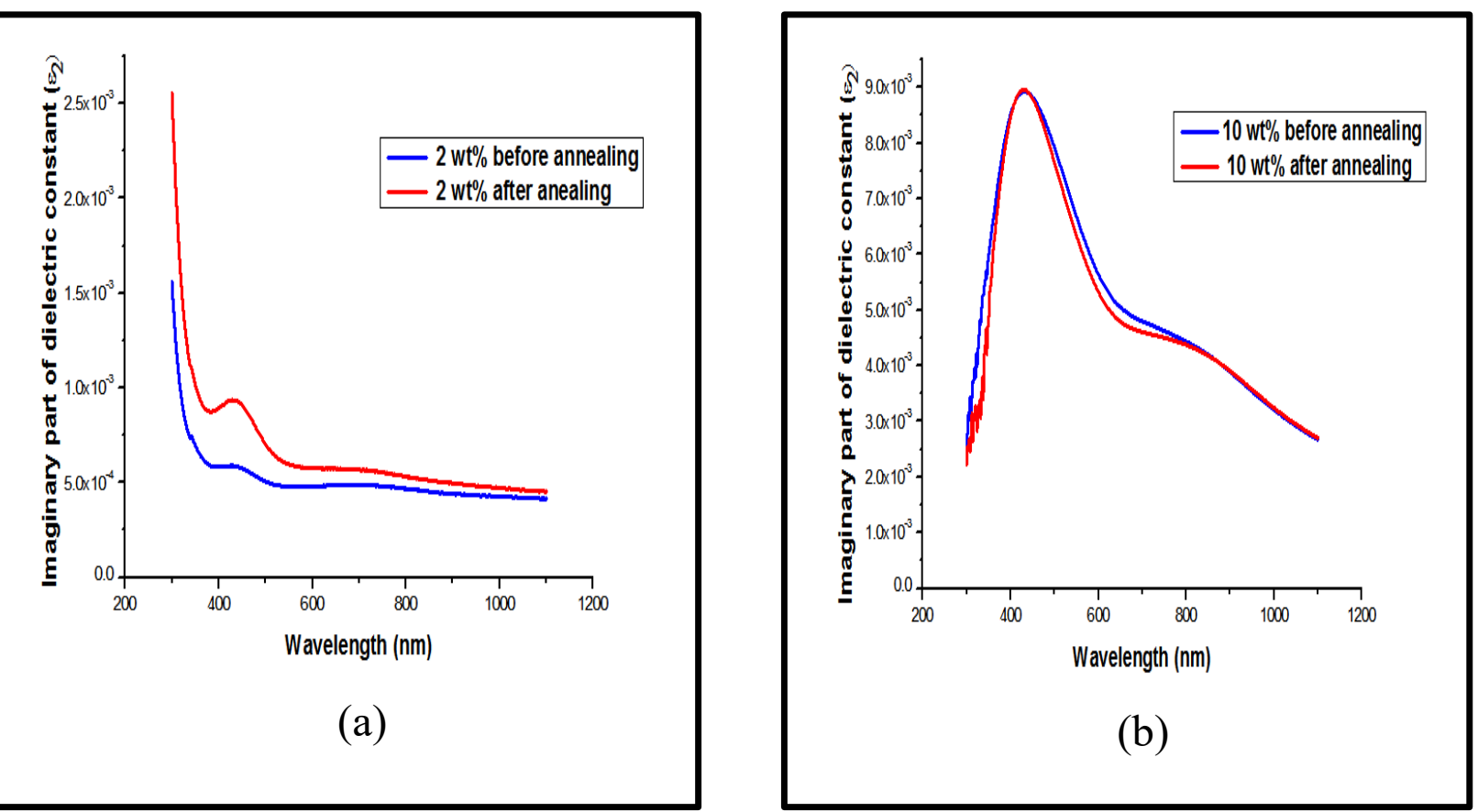

Figure (8): The imaginary part of dielectric constant of (PVA-CuCl) films with 2 and $10 \mathrm{wt} \%$ concentrations of $\mathrm{CuCl}$ salt as a function of the wavelength (a) before annealing and (b) after annealing.

\section{4- CONCLUSIONS}

1- The absorbance and the absorption coefficient of (PVA-CuCl) films increased after annealing for all the films.

2- The energy gap $\left(\mathrm{E}_{\mathrm{g}}\right)$ of allowed indirect transition of $(\mathrm{PVA}-\mathrm{CuCl})$ films decreased after annealing for all the films.

3- For (PVA-CuCl) films the refractive index, extinction coefficient, real and imaginary parts of dielectric constant increased after annealing for all the films.

4- The annealing process gives agood results of the optical properties for (PVA-CuCl) composite films.

\section{References}

[1] V.R. Gowariker, N. V. Viswanathan and J. Sreedhar, "Polymer Science", New Age International, New Delhi, (2005).

[2] K. Bula, T. Jesionowski and S. Borysiak, "Effect of injection molding conditions on composite properties based on PBT with $\mathrm{SiO}_{2}$ and MMt Nanofillers", Proceedings of the Conference of Multiphase Polymers and Polymer Composites: From Nanoscale to Macro Composites", Paris-Est, Creteil Uniersity, June, France, (2011).

[3] V. Singh, A. R. Kulkarni and T. R. Rama, "Dielectric properties of aluminum-epoxy composites", Journal of Applied polymer Science, Vol. 90, No. 13, pp. 3602-3608, 20 December (2003).

[4] M. Mahsanl, C. Shengl, M. Isal, E. Ghapur, E. Ali and M. Razali, "Structural and physical properties of $\mathrm{PVA} / \mathrm{TiO}_{2}$ composite", Malaysia Polymer International Conference, (2009).

[5] A. Tawansi, M. D. Migahed and M. I. A. El-Hamid, "Part B: Polymer physics", Journal of Polymer Science, Vol. 24, No. 12, pp. 2631, (1986). 
[6] O. G. Abdullah and D. R. Saber, "Optical absorption of Polyvinyl alcohol films doped with Nickel Chloride", Applied Mechanics and materials, Vol. 110-116, pp. 177-182, (2012).

[7] A. Hashim, M. Ali and B. H. Rabee, "Optical properties of (PVA-CaO) composites", American Journal of Scientific Research, No. 69, pp. 5-9, (2012).

[8] M. Abdallh, O. Hamood and E. Yousif, "Study the optical properties of Poly (vinyl alcohol) doped Copper Chloride", Journal of Al-Nahrain University, Vol. 16, No. 1, pp. 17-20, (2013).

[9] B. G. Strectman and S. Banerjee, "Solid State Electronic Devices"5 $5^{\text {th }}$ ed., Engle Wood Cliffs, $\mathrm{Nj}$, Prentice Hall (2000).

[10] C. Mwolfe, N. Holouyak and G. B. Stillman, "Physical Properties of Semiconductor", Prentice Hall, New York, (1989).

[11] J. I. Langford and A. J. C. Wilson, "Scherrer after sixty years: a survey and some new results in the determination of crystallite size", Journal of Applied Crystallography, Vol. 11, No. 2, pp. 102-113, (1978).

[12] D. K. Dwivedi, V. Kumar, M. Dubey and H. P. Pathak, " Structural, electrical and optical investigations of CdSe nanoparticles", Chalcogenide Letters, Vol. 8, No. 9, pp. 521 - 527, September (2011).

[13] S. M. Sze and K. Ng. Kwok, "Physics of Semiconductor Devices", John Wiley and Sons, Inc., Hoboken, New Jersey, (2006).

[14] N. Fadhil Habubi, Z. AI-Ramadhan and R. Ismaee khaleel "Annealing effect on optical Properties of Poly (Vinyl Chloride) modified by Nickel eyhyl xanthate chelate complex" Proceeding of 3rd Scientific conference of the College of Science, University of Baghdad, pp. 2080-2087, March (2009).

[15] K. L. Chopra and I. kaur, "Thin films Device Applications", Plenum Press, New York, (1983).

[16] R. Berglund, P. Graham and R. Miller, "Applications of In-situ FT- IR in pharmaceutical process R and D", Spectroscopy, Vol. 8, No. 8, pp. 31-38, (1993).

[17] C. Klingshirn, "Semiconductor Optics", Verlag Berlin Heidelberg, (1997). 